\title{
Is hormone replacement therapy protective for hand and knee osteoarthritis in women?: The Chingford study
}

\author{
T D Spector, D Nandra, D J Hart, D V Doyle
}

\begin{abstract}
Objectives-To explore whether hormone replacement therapy (HRT) has a protective role for osteoarthritis (OA) of the hand and knee in a cross sectional study of women in the general population.

Methods-1003 women aged 45-64 (mean age 54.2) from the Chingford Study were asked details of HRT use. Standard anteroposterior radiographs of hands, knees were taken and scored according to the methods of Kellgren and Lawrence (grade 2+ positive for OA), and using individual features of osteophytes and joint space narrowing. Analysis compared ever use ( $>12$ months) versus never use, and current use ( $>12$ months) versus never use. Only 606 definitely postmenopausal women were included in the analysis. Odds ratios and $95 \%$ confidence intervals were calculated using logistic regression for risk of user versus non-user at each site, adjusted for age, height and weight, menopausal age and for bone mineral density of the femoral neck.
\end{abstract}

Results-For current users $(n=72)$ there was a significant protective effect of HRT for knee OA (defined by Kellgren and Lawrence grade or osteophytes 0.31 (95\% CI 0.11, 0.93), and a similar but not significant effect for moderate joint space narrowing of the knee, 0.41 (95\% CI 0.05 , 3.15) and for distal interphalangeal $O A$ $0.48(95 \%$ CI $0.17,1.42)$. No clear effect was seen for the carpometacarpal joint, CMC OA 0.94 (95\% CI 0.44, 2.03). When analysing ever users $(n=129)$ the protective effect was reduced. For ex-users of $>12$ months (mean duration $\mathbf{4 0 . 7}$ months), there was no overall protective effect of HRT for OA. Additional adjustment for hysterectomy, physical activity, social class, and smoking made little difference to the results.

Conclusions-These data show an inverse association of current HRT use and radiological OA of the knee suggestive of a protective effect. The effect was weaker in the hand joints. The mechanism of the protection is unclear but has important implications for aetiopathogenesis.

(Ann Rheum Dis 1997;56:432-434)

Hormone replacement therapy (HRT) use is increasing worldwide because of its beneficial effects on menopausal symptoms, bone mineral density, heart disease, and cerebrovascular disease. Osteoarthritis (OA) is the most common cause of disability in most developed countries. A number of findings suggest that female sex hormones have a role in triggering OA. These include the frequent onset of generalised disease around the time of the menopause, and the fact that OA is less common in women with osteoporosis, ${ }^{1}$ a disease associated with oestrogen deficiency. A previous study of knee OA in the elderly has suggested a weak non-significant protective effect of HRT, but numbers of users were small. ${ }^{2}$ We therefore examined whether the use of HRT in middle aged women was associated with the development of radiological OA at different joint sites.

\section{Methods}

A total of 1003 women in the age range 45-64 (mean 54.2) were recruited between 19871989 from an age/sex register of a large general practice of over 11000 patients in Chingford, north east London with a response rate at recruitment of $78 \%{ }^{1}$ The population is similar to the UK population in terms of height, weight, smoking status, and HRT use. The socioeconomic profile was performed using the Acorn classification system, which is based on each subjects postcode and place of residence (CACI International, London). The social class mix is made up of four main groups, $32 \%$ were high social class (A/B), $42 \% \mathrm{C} 1,17 \% \mathrm{C} 2$, and $8 \% \mathrm{D} / \mathrm{E}$. Standard anteroposterior radiographs of the hand and weight bearing extended views of the knees were available for 985 women.

OA cases were defined radiologically using standard epidemiological classification. Radiographs were scored by a single trained observer blinded to clinical details. Hand OA affecting the distal interphalangeal (DIP) or carpometa- 
carpal (CMC) joint was defined as grade $2+$ in more than one finger for the DIP and one site for the CMC using the global Kellgren and Lawrence 0-4 scale. ${ }^{3}$ Proximal interphalangeal joint OA was too infrequent for analysis. An atlas of individual features (0-3) was used to classify grade 1 osteophytes equivalent to grade 2 Kellgren and Lawrence. For joint space narrowing, an atlas grade $1+$ was used for the tibiofemoral knee joint for defining mild joint space narrowing and grade $2+$ moderate joint space narrowing. Bone density of the femoral neck was measured using Hologic QDR 2000 DXA machine with an error of approximately $1.3 \%$ in our hands.

A nurse administrated questionnaire was used to obtain demographic and environmental details. Where information on timing and duration of HRT use or age at menopause was unclear, additional information was obtained by subsequent telephone survey and postal questions. Current users were defined as more than 12 months of use at the time of radiography and ex-users more than 12 months at least 24 months previously. Age at menopause was defined as last recalled regular menses or oophorectomy. Women were defined as postmenopausal if their periods had stopped at least 12 months previously, or if they had a total hysterectomy, or hysterectomy alone and were aged over 55 . Odds ratios and $95 \%$ confidence intervals were calculated using multiple logistic regression (EGRET, SERC, Seattle) for the risk of $\mathrm{OA}$ in users versus never users adjusting for potential confounders, age, height, weight, menopausal age, femoral neck BMD, as well as hysterectomy physical activity, recalled knee injury, and social class.

\section{Results}

Subjects were divided into three exposure categories; current users (more than 12 months, mean duration (SD) 33.4 months (26.5) $\mathrm{n}=72$ ), ever users (a combination of ex-users (at least two years before radiography) and current users for more than 12 months, mean duration (SD) 36.6 months (29.5) $\mathrm{n}=129)$ and never users (including those users of less than 12 months) $(n=874)$. The types of HRT were recorded and the majority of users had taken conjugated oestrogens, Prempak-C or Premarin 0.625 at some time. Table 1 shows a comparison of the groups. No difference between HRT groups was seen for age, height, weight, and BMI. As expected the 129 women in the ever HRT group had a significantly increased mean (SD) femoral neck BMD (0.79 $(0.12) v 0.76(0.12) \mathrm{p}=0.03)$ and higher rates of hysterectomy. Levels of smoking and physical activity were similar. There were significant differences in social class between the groups. Only women who were clearly postmenopausal at the time of the radiography were included in the HRT analysis $(n=606)$. If women had undergone hysterectomy and bilateral oophorectomy $(n=65)$, their age at menopause was taken as the age at operation. Women under 55, with hysterectomy alone $(n=165)$, were excluded. Prevalence and risk of OA at each site by HRT status is shown in table 2 adjusted for age, height weight, menopausal age, and bone density. For current users there was a threefold significant protective effect of knee OA as defined by osteophytes OR 0.31 $(95 \%$ CI $0.11,0.93)$, and a twofold non-significant protective effect for the DIP OR 0.48 (95\% CI $0.17,1.42)$. No clear effect was seen at the CMC joint OR 0.94 (95\% CI $0.44,2.03)$. For joint space narrowing at the knee, there was no clear effect for mild (grade 1) narrowing, but a suggestion for more severe narrowing $\mathrm{OR}=0.41$ (95\% CI $0.05,3.15)$, although numbers were small in this latter group. When analysing ever users the protective effect was generally lessened and non-significant. There were only a small number (57) of ex-HRT users and no suggestion of a protective effect was seen. Additional adjustment for further potential confounders such as social class, hysterectomy, oophorectomy, physical activity, and knee injury did not further change the results.

\section{Discussion}

These data show that current use of HRT is associated with a threefold reduction in risk of knee OA, as defined by osteophyte or Kellgren and Lawrence and a modest reduction in DIP but not CMC OA. There was a suggestion of an effect when defining knee OA by moderate joint space narrowing but not mild, although numbers were small. This effect was not mediated by change in bone density or explained by measured confounders. We had insufficient numbers of long duration users to accurately assess dose response. The differences between the effects of past and current HRT use are

Table 1 Basic characteristics of women, presented as mean (SD) or number (\%)

\begin{tabular}{|c|c|c|c|c|c|c|}
\hline & & Current $(n=72)$ & Ex-users $(n=57)$ & Ever $(n=129)$ & Never $(n=874)$ & $\begin{array}{l}\text { p Value } \\
\text { ever } \mathrm{v} \\
\text { never }\end{array}$ \\
\hline Age (y) (SD) & & $53.5(4.53)$ & $54.6(6.1)$ & $53.9(5.29)$ & $54.3(6.13)$ & 0.64 \\
\hline Age menopause (y) (SD) & & $48.7(3.73)$ & $46.3(5.6)$ & $48.5(3.77)$ & $48.9(4.18)$ & 0.42 \\
\hline Duration HRT (months) (SD) & & $33.4(26.46)$ & $40.7(32.7)$ & $36.6(29.49)$ & N/A & \\
\hline Height $(\mathrm{cm})(\mathrm{SD})$ & & $161.9(6.02)$ & $161.74(5.86)$ & $161.8(5.93)$ & $161.6(6.0)$ & 0.31 \\
\hline Weight (kg) (SD) & & $66.3(13.41)$ & $66.3(8.93)$ & $66.3(11.60)$ & $67.0(11.88)$ & 0.52 \\
\hline $\mathrm{BMI}(\mathrm{SD})$ & & $25.3(4.68)$ & $25.4(3.47)$ & $25.33(4.18)$ & $25.6(4.32)$ & 0.43 \\
\hline Hysterectomy (\%) & & $32(44.4)$ & $22(38.6)$ & $54(41.9)$ & $176(20.1)$ & $<0.001$ \\
\hline Smoking (\%) ever & & $30(41.7)$ & $36(63.2)$ & $66(51.2)$ & $397(45.4)$ & 0.22 \\
\hline \multirow[t]{2}{*}{ Physical activity group (\%) } & Low & $4(5.6)$ & $3(5.3)$ & $8(6.3)$ & $24(2.5)$ & 0.43 \\
\hline & High & $8(11.1)$ & $6(10.5)$ & $14(10.9)$ & $75(8.6)$ & \\
\hline \multirow[t]{3}{*}{ Social classes (\%) } & $\mathrm{A} / \mathrm{B}$ & $35(48.6)$ & $19(33.9)$ & $54(41.9)$ & $265(30.3)$ & \\
\hline & $\mathrm{C}_{1}$ & $23(31.9)$ & $25(44.6)$ & $48(37.2)$ & $375(42.9)$ & 0.03 \\
\hline & $\mathrm{C}_{2} / \mathrm{D}$ & $14(28.1)$ & $12(21.5)$ & $25(19.4)$ & $231(26.4)$ & 0.01 \\
\hline BMD femoral neck (SD) $\left(\mathrm{g} / \mathrm{cm}^{2}\right)$ & & $0.80(0.13)$ & $0.77(0.11)$ & $0.79(0.12)$ & $0.76(0.12)$ & 0.03 \\
\hline
\end{tabular}


Table 2 Prevalence of $O A$ and risk of $O A$ by HRT group presented as odds ratios and $95 \%$ confidence intervals

\begin{tabular}{|c|c|c|c|c|c|c|c|}
\hline \multirow[b]{3}{*}{ foint site and $O A$ grade } & \multirow{3}{*}{$\begin{array}{l}\text { Number } \\
\text { affected (\%) }\end{array}$} & \multicolumn{3}{|c|}{ Current users $(n=72)$} & \multicolumn{3}{|c|}{ Ever users $(n=129)$} \\
\hline & & \multicolumn{2}{|c|}{ Affected (n) } & \multirow{2}{*}{$\begin{array}{l}\text { Adjusted }{ }^{\star} \text { odds } \\
\text { ratios }+95 \% C I\end{array}$} & \multicolumn{2}{|c|}{ Affected (n) } & \multirow{2}{*}{$\begin{array}{l}\text { Adjusted }{ }^{\star} \text { odds } \\
\text { ratios }+95 \% \text { CI }\end{array}$} \\
\hline & & Cases & Controls & & Cases & Controls & \\
\hline $\begin{array}{l}\text { Knee osteophytes } \\
\text { Knee narrowing }\end{array}$ & $143(14.5)$ & 4 & 68 & $0.31(0.11,0.93)$ & 15 & 112 & $0.80(0.43,1.49)$ \\
\hline Gd1+ & $359(36.7)$ & 20 & 52 & $0.70(0.41,1.22)$ & 49 & 78 & $1.21(0.81,1.81)$ \\
\hline $\mathrm{Gd} 2+$ & $34(3.5)$ & 1 & 71 & $0.41(0.05,3.15)$ & 4 & 123 & $1.00(0.34,2.96)$ \\
\hline $\begin{array}{l}\text { Distal interphalangeal joint } \\
\text { OA }\end{array}$ & $140(14.2)$ & 4 & 50 & $0.48(0.17,1.42)$ & 12 & 87 & $0.67(0.34,1.35)$ \\
\hline Carpometacarpal joint OA & $160(16.2)$ & 9 & 50 & $0.94(0.44,2.03)$ & 13 & 87 & $0.65(0.34,1.23)$ \\
\hline
\end{tabular}

*Adjusted for age, height, weight, menopausal age, femoral neck BMD.

unclear but could reflect a temporal relation. Other epidemiological studies of the effects of HRT on osteoporosis and cardiovascular disease have shown similar results; namely that current use is associated with a $50 \%$ protective effect but that ex-use conveys no detectable protective effect if stopped for three to five years previously. ${ }^{56}$ The cross sectional nature of the study makes it difficult to be sure of a true temporal relation. Why as little as three years of HRT should have a demonstrable effect is unclear. Given the difficulty in ascertaining when the disease starts, it is hard to be sure of the importance of the timing of HRT, and whether early or subclinical disease was present. These results taken together suggest that HRT has a metabolic action that is only effective if given continuously, perhaps by preventing disease initiation; once HRT is stopped there might be a 'rebound' effect, explaining the rapid return to normal risk. In OA the mechanisms by which HRT might act are highly speculative, but could entail changes in cartilage repair or bone turnover, perhaps with cytokines such as interleukin 6 , for example. ${ }^{7}$ The study of knee OA in elderly women by Hannan et al lacked sufficient numbers of current users to resolve the issue of timing. ${ }^{2} \mathrm{~A}$ case control study of knee OA by Samanta et al examined HRT use as one of a number of potential risk factors and found a non- significant protective effect but did not distinguish timing of HRT use. ${ }^{8}$ A recently published study by Nevitt et al from the Study of Osteoporotic Fractures cohort of 4366 white women reported that in current users the risk of hip OA was 0.62 (95\% CI $0.49,0.86)$, with a weak trend for increasing protection with disease severity. ${ }^{9}$ As in this study no clear effect for past use was seen. In observational studies of HRT use such as this, selection bias is a potential problem that is impossible to completely eliminate by adjustment. Although we found no major differences in our data other than for social class, studies have shown that long term HRT users are more likely to be health conscious, have better diets, and be better informed about preventive medicine. ${ }^{10}$ Nevertheless the size of the effect, the increasing use of HRT, and the public health importance of OA warrant confirmatory prospective studies and ideally a randomised trial. As previous studies have shown bone density is higher in women with $\mathrm{OA},{ }^{1}$ a reasonable hypothesis was that HRT use could lead to a greater risk of OA. ${ }^{11}$ Spector and Campion proposed in 1988 a hypothesis that OA was a disease triggered by oestrogen excess, based on a variety of animal, and epidemiological observation data. ${ }^{11}$ The contrasting findings here suggest that it may be superficial to label oestrogens as good or bad. The changes in concentrations may be as important as the absolute values, or alternatively HRT may prevent the sharp changes perimenopausally that trigger OA. Whatever the real reason, it shows how little we know of the mechanisms of action of oestrogens on bone and cartilage. ${ }^{12}$ Understanding these mechanisms has the potential to uncover new therapeutic avenues.

We are grateful to Sabeha Attia, Maxine Daniels, and Elizabeth Arden for their input as well as the staff of Chingford Hospital and the staff and patients of the Handsworth Avenue Health Partnership.

1 Hart D J, Mootooswamy I, Doyle D V, Spector T D. The relationship between osteoarthritis and osteoporosis in the general population: The Chingford Study. Ann Rheum Dis 1994;54:158-62.

2 Hannan MT, Felson DT, Anderson JJ, Naimark A, Kannel WB. Estrogen use and radiographic osteoarthritis of the knee in women. Arthritis Rheum 1990;33:525-32.

3 Kellgren J H, Jeffrey M R, Ball J. The epidemiology of chronic rheumatism: atlas of standard radiographs. Vol 2. Oxford: rheumatism: atlas of standard

4 Burnett S, Hart D J, Cooper C, Spector T D. A radiographic atlas of osteoarthritis. London: Springer Verlag, 1994.

5 Colditz GA, Hankinson SE, Hunter DJ, Willett WC, Manson JE, Stampfer MJ, et al. The use of estrogens and progestins and the risk of breast cancer in postmenopausal women. N Engl J Med 1995;332:1589-93.

6 Cauley JA, Seeley DG, Ensrud K, Ettinger B, Black D, Cummings SR. Estrogen replacement therapy and fractures in older women. Study of osteoporotic fractures Research Group. Ann Intern Med 1995;122:9-16.

7 Guerne P-A, Carson DA, Lotz M. IL-6 production by human articular chondrocytes: modulation of its synthesis by cytokines, growth factors and hormones in vitro. J by cytokines, growth factors
Immunol 1990;144:499-505.

8 Samanta A, Jones A, Regan M, Wilson S, Doherty M. Is osteoarthritis in women affected by hormonal changes or smoking? Br J Rheumatol 1993;32:366-70.

9 Nevitt MC, Cummings SR, Lane NE, Hocnberg MC, Scott JC, Pressman AR, et al. Association of estrogen replacement therapy with the risk of hip osteoarthritis in elderly white women. Arch Intern Med 1996;156:2073-80.

10 Posthuma WF, Westendorp RG, Vandenbroucke JP. Cardioprotective effect of HRT in postmenopausal women: Is evidence biased? BMJ 1994;308:1268-9.

11 Spector TD, Campion GD. Generalised OA. A hormonally mediated disease. Ann Rheum Dis 1989;48:523-7.

12 Nevitt MC, Felson DT. Sex hormones and the risk of osteoarthritis in women: epidemiological evidence. Ann Rheum Dis 1996;55:673-6. 